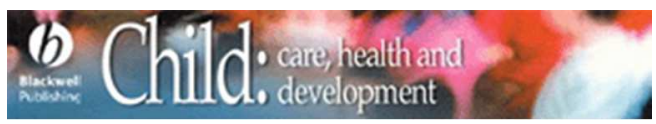

\title{
Seeing it my way: living with childhood onset visual disability
}

\begin{tabular}{|r|l|}
\hline Journal: & Child: Care, Health \& Development \\
\hline Manuscript ID: & Draft \\
\hline Manuscript Type: & Research Article \\
\hline Keywords: & Visual Impairment, Childhood Disability, Childrens` Views, Quality Of Life \\
\hline \multicolumn{2}{|c}{} \\
\end{tabular}

SCHOLARONE $^{\text {"x }}$

Manuscripts 


\section{ABSTRACT}

Background: Although the significant impact of visual disability in childhood has been widely recognised, children's own perspectives of living with a visual impairment have not been considered. We report the experiences of visually impaired (VI) children and young people aged 10-15 years about growing up with impaired sight.

Methods: The participants were 32 VI children and young people, aged 10-15 years (visual acuity LogMAR worse than .51) recruited through NHS paediatric ophthalmology and developmental vision clinics and 11 VI pupils aged 12-17 recruited attending a specialist school for pupils with disabilities. Individual semi-structured interviews with participants captured their experiences of living with a visual impairment. A child-centred interview topic guide was developed from a literature review, observations at ophthalmology clinics, consultation with health and education professionals working with VI children and young people, and interviews and a focus group with VI pupils from the specialist school. Collaborative qualitative thematic analysis by three researchers identified emergent themes. NVivo software was used for coding the data.

Results: Analysis identified 6 themes concerning living with a visual impairment: a)social relationships, participation and acceptance, b)independence and autonomy, c)psychological and emotional wellbeing, d)aspirations and concerns about the future, e)functioning at home, school and leisure, and f)treatment of eye condition. Key issues included: the importance of family and peer support; balancing independence, support and safety; the emotional burden and adjustment of living with a disability; concerns about education and job prospects in the future; functional restrictions and limitations; and on-going management of the eye condition.

Conclusions: The findings offer insights into the complex realities of living with visual impairment. They provide the basis for development of patient-reported outcome measures. 
They can also serve to help enrich the understanding of health professionals working with VI children and young people, potentially enabling them to better support them. 


\section{INTRODUCTION}

Research using innovative child-centred methodologies has demonstrated the great value of asking for children's views of their health condition and the healthcare they receive (Horstman \& Bradding, 2002; Garth \& Aroni, 2003; Klostermann et al., 2005; Pelander et al., 2007; Davies et al., 2009; Moules, 2009; Gibson et al., 2010).

Visual impairment impacts on all aspects a child's/young person's life, with far reaching consequences for development, social adjustment, emotional wellbeing and education(Curry \& Hatlen, 1988; Preisler, 1991; McConachie \& Moore, 1994; Warren, 1994; Hatton et al., 1997; Taylor, 1997; Kef, 2002; Ophir-Cohen et al., 2005). It shapes the life they lead as adults, impacting particularly on employment and social experiences (Freeman et al., 1991; Nagle, 2001; Shaw et al., 2007). However, visually impaired (VI) children's perspectives of the consequences of their impaired sight have not been widely examined.

Although, quality of life (QoL) is an important patient-reported outcome in paediatric health research (Bullinger \& Ravens-Sieberer, 1995; Eiser \& Morse, 2001), robust measures of QoL of VI children and young people ${ }^{1}$ are scarce. We have recently completed research to develop a questionnaire that measures vision-related QoL (VQoL) of VI children aged 10-15 years (Rahi et al., 2011). The content of our questionnaire was identified through individual interviews with children about the impact of living with impaired sight. Here, we describe the concerns and issues they raised in these interviews to enhance clinicians' understandings of the lives of their young visually impaired patients.

\section{METHODS}

The study was approved by the Research Ethics Committee for Great Ormond Street Hospital (GOSH) NHS Trust and UCL Institute of Child Health, London, UK and adhered to the tenets of the Declaration of Helsinki.

\footnotetext{
${ }^{1}$ For brevity, we use term children in the remainder of the paper.
} 


\section{Patient identification and recruitment}

Participants were identified from the hospital databases and clinical records of patients attending the Ophthalmology Department or Developmental Vision Clinic at GOSH and the Paediatric Glaucoma service or Genetic Eye Disease service at Moorfields Eye Hospital (MEH) in London, UK. The sampling frame of eligible patients comprised those with: a) corrected visual acuity in the better eye worse than $0.51 \operatorname{LogMAR}$ (in keeping with the World Health Organization/WHO taxonomy; WHO, 2003) due to any condition but in absence of any other significant sensory motor or intellectual impairment, and b) aged 10-15 years. This age group was selected to take into account the optimal age and communication skills required to be interviewed and reliably self-report, as well as the maturation of the human visual system and the natural history of most visually impairing disorders of children.

Of 376 patients in the sampling frame, 107 were invited, using a stratified sampling approach (with over recruitment of ethnic minority groups who are disproportionately at risk of VI in UK, Rahi \& Cable, 2003), to participate in individual semi-structured interviews. The achieved sample of 32 participants (18 girls, 14 boys) was representative of the VI population in terms of age, gender and clinical characteristics, although participants from white $(N=24)$ and affluent socio-economic backgrounds $(\mathrm{N}=12)$ were over-represented compared to the total eligible population in the sampling frame (Tadić et al., 2010). Twenty four participants were VI $\left(\operatorname{LogMAR}{ }^{2}\right.$ range $\left.=.051-1.00\right)$ and 8 were severely VI (SVI) or blind (BL) (WHO, 2003). Twenty five participants had early onset visual impairment (defined as $<2$ years of age). Informed written consent for participation was obtained from the parents and verbal assent from participants.

A group of 11 SVI young people (12-17 years old) at a specialist school for pupils with a range of disabilities in UK were recruited and participated (with pupil assent and parent and head teacher consent, as an 'expert reference group') advising on the study methodology.

\footnotetext{
${ }^{2}$ Logarithm of Minimum Angle of Resolution
} 


\section{Procedures}

Face-to-face individual semi-structured interviews lasting up to an hour were conducted by a trained interviewer ( 25 at the participant's home, 7 at school or hospital). All were digitally recorded and transcribed. Twenty interviews were conducted without a parent present and 12 with a parent observing.

The interview topic guide combined information from a wide literature review (concerning visual impairment, childhood disability and the existing measures of QoL for children and adults) with observations at the paediatric ophthalmology clinics. Our expert reference group was consulted in refinement of the topic guide through further discussion.

Piloting of the topic guide with 2 boys and 2 girls aged 12 - 16 years from our expert reference group confirmed the importance of verbal encouragement. The final topic guide had 6 main topics: School; Home Life; Activities and Socialising; Life Skills and Independent Living; Future; and Eye problems and the Eye Clinic.

Collaborative data analysis ensured inter-rater reliability and rigour. The data coding template using NVivo7 was developed through discussion between 3 researchers who independently read and coded 4 interviews, and agreed emergent themes and lower-order descriptive categories. Four further interviews were coded independently by 2 researchers and compared, resulting in adjustments. The remaining coding was undertaken by one researcher with discussion, as required, if any new categories were identified (Silver \& Lewins, 2007). Three researchers reviewed the coded transcripts, coded into lower-order descriptive categories and separated by age groups (10-12 and 13-15 years), to identify whether there were any specific agerelated topics and independently identified higher-order, more overarching themes.

\section{RESULTS}

We identified six overarching themes from the interviews:

- Social relationships, participation and acceptance 
- Independence and autonomy

- $\quad$ Psychological and emotional well being

- Aspirations and concerns about the future

- $\quad$ Functioning at home, school and leisure

- Treatment and understanding of eye condition

We report the key issues raised by participants within these themes, with illustrative verbatim quotes presented to demonstrate the subtleties and complexities of the impact of visual impairment.

\section{Social relationships, acceptance and participation}

Participants talked about relationships with family, friends and other important people like teachers and learning support assistants (LSAs). These were seen as providing the anchor for social inclusion, acceptance and support.

'I look forward to coming into school seeing all my friends, and I mean the teachers, they're like second mums really.' (girl, 14, SVI, late onset)

'My cousins don't treat me any different, they treat me the same as they treat their other cousins, so we always get treated the same at like, my aunties treat us the same, none of us get more attention and all that, like some people do.' (boy, 13, blind, early onset)

Nevertheless, some participants felt overprotected by their families, with a negative impact on their autonomy and social participation.

I'm never allowed to go out into town because I'm not trusted. I'm not trusted even with my mate. Still treated like a baby, I hate it.' (boy, 11, blind, early onset)

'I don't know what I'd do without this [guide] dog...I'm using her more as a 'get out with my friends' sort of thing because then I have an excuse to go out without getting the evils from my father.' (girl, 13, VI, early onset)

Peer relationships were mostly discussed in relation to school, including differences between specialist versus mainstream settings. Within mainstream schooling, the importance of 
teachers and teaching assistants (TAs)/LSAs was appreciated, but was also perceived as preventing participants from being like everyone else.

'When she's here I feel left out of games, but she still talks to me and I do have fun with her, but then when she doesn't come I get to play more freely.' (girl, 10, SVI, early onset)

Some activities such as sport or break times were experienced as difficult, with some interviewees reporting feeling excluded, isolated or being bullied. Although some participants reported getting on well in the mainstream system, those attending specialist VI schools, in particular those who had moved from mainstream settings, reported examples of social acceptance and being treated more fairly.

'You get treated more like an adult at this [specialist VI] school. They just talk. to me normally, and they just don't make me feel like some kind of kid.' (boy, 11, blind, early onset)

In mainstream they shout too much, they don't pay attention to people that have got eyesight problems, but in special schools they are patient with you.' (boy, 13, blind, early onset)

The desire to 'fit in' and be 'normal was mentioned frequently. Whilst many interviewees exhibited resilience and adjustment to living with a visual disability (see Psychological and emotional wellbeing), for some participants being the only one with a visual impairment in a sighted context appeared to increase awareness of 'having a problem'.

I just want to be normal and that but every time I like write in large print it just like always like reminds me that I've got problems.' (boy, 12 , VI, late onset)

I just can't do [sports], and I want to be a part of it but I just can't so I just feel as though I get left out all the time.' (boy, 12, VI, late onset)

Having good friends, regardless of educational setting, appeared to be an important factor in overcoming feelings of isolation and exclusion.

'In the cinema my friends ask me where I want to sit and where I can see.' (girl, 12, VI, early onset)

My mates don't tease me about it, they include me whatever disabilities I have, and they just stick up for me.' (boy, 12, VI, late onset) 
A number of participants reported being bullied or teased by peers, with notable variation in coping strategies.

'Some people try tripping me up in the corridors because they think it's funny because I can't see their feet.' (boy, 12, VI, early onset)

They call me blind and take the rip out of me... I go bome every night and I just sit there, sometimes I just burst into tears and sometimes I'm just really laid back about it.' (boy, 11, blind, early onset)

Additionally, participants felt that their visual disability led to stigmatisation by others.

They frequently expressed frustrations about other people not having an understanding of what it is like to be VI, and the limitations posed by it, especially when it was not an obvious impairment.

'At school I always got blamed for everything that went wrong because I just seemed to be an easy blameable target' (girl, 15, VI, early onset)

'Questions are annoying, they're always like: "Do you see different to us?" and I'm like: "How do I know? I've never seen like you!'.' (girl, 11, VI, early onset)

I was crossing the road to go to the shop and this bloke turned, then he started shouting at me... it was funny but he had a go at me saying "Can't you see that my blinker was on?!" and I went "No, actually I couldn't”' (girl, 13, VI, early onset)

Interviewees spoke about having fewer opportunities for spontaneous socialising, for example, because they avoided queues in the school canteen or a busy playground because of the physical challenges of managing the hustle and bustle. Others described how access to leisure and sports activities that were suitable or adapted to their needs provided opportunities to meet peers with visual disability as well as enhancing their participation in sport.

'[At a specialist school] there is a lot of activities that you wouldn't probably be able to do if you had a visual impairment at home and that is what's so good about this school. I'd probably never been able to go ice skating... but here you have a guide...people who are blind, they're just whizzing round.' (girl, 14, SVI, late onset)

'During a holiday activity] I preferred the [coal] mine because I was the same as everyone else, no one else could see.' (boy, 10, SVI, early onset) 
Independence and autonomy

Participants revealed significant impact of visual disability on their independence, including their reliance on family members when travelling (e.g. to meet up with friends in town), shopping (e.g. choosing the right clothes size), handling money (e.g. telling coins and notes apart and checking the correct change ), choosing e clothes, making food and drinks and telling the time. Most participants acknowledged the family as an important source of support, but were conscious of the trade-off with independence. For instance, older participants discussed that their reliance on parents to read and write text messages and emails could be a barrier to privacy and subsequently to their relationships with peers, despite many using voice activated computer software and adjusted screen font.

'When on MSN], when changing conversation then I have to get someone to belp set it up big. I never get any private time to myself.' (girl, 14, SVI, early onset)

Participants accepted that without support, their safety could be compromised (e.g. handling knifes and hot water, crossing roads or getting on and off the right bus).

The balance between support, independence and autonomy was discussed with regards to school. Notably, support from TAs/LSAs in mainstream schools could have a negative effect on the child/young person's wish to fit in. Equally, adaptive technologies (e.g. CCTV, Zoom text), whilst facilitating functioning and greater independence could also be a source of frustration and social embarrassment.

'Just the idea of going to senior school and having someone trailing around after you........it really wouldn't have helped with the whole like blending in, making friends in school thing.' (girl, 15, VI, early onset)

'I have to sit next to a [teachers' assistant in lessons] and not get to sit next to friends or people I hate. I mean I'd prefer sitting next to people I hate than [teachers' assistant].' (girl, 13 years, visually impaired, early onset)

Independent mobility was important for all. Most viewed a guide dog or cane as a positive thing and some young people highlighted the value of mobility training in increasing 
their independence. A small number of interviewees, however, showed resistance and dislike of mobility training and devices, feeling it compromised their prospects for social inclusion and fitting in.

'They tried to get me with a symbol stick [as part of mobility training] but I'm not using it, I don't need it. It's to tell everyone I'm partially sighted. I don't care; I am going to be just as normal as everyone else.' (girl, 13, VI, early onset)

\section{Psychological and emotional well-being}

Several dimensions of well-being were reported to be affected by visual disability. The uncertainty surrounding the visual prognosis and future prospects, as well as the practicalities of daily living), had a significant emotional impact. Participants frequently voiced disappointment and frustration associated with the stigma of having a visual impairment, highlighting the impact on their confidence and self-esteem.

\footnotetext{
'It's only in the past 1-2 years that it feels like [my eyesight] got worse, but it hasn't, it just feels worse because of how it's affected me.' (boy, 12, VI, early onset)

I just want to be normal and that but, every time I like write in large print it just like always like reminds me that I've got problems and that like, it just gets annoying, I just think "What's the point in living?".' (boy, 12, VI, late onset)
}

The effect on self-image (appearance of the eye, wearing glasses or contact lenses) was also evident.

When I meet boys and look them in the eye, they see my eyes wobble. That's what might put them off...If there was like a surgery to stop my eyes wobbling, I wouldn't care about my eye problem, it's just the wobbling; that's what affects me the most' (girl, 12, VI, early onset)

The psychological impact of sight loss acquired during childhood (late onset visual impairment) appeared to be more traumatic than growing up with impaired vision (early onset VI).

I woke up one day and I was blind. I went to the optician and they said there was nothing wrong with me because there isn't actually anything wrong with the eye, it's the optic nerve. So I think they 
thought I was making it up, because I had SATs [standardised school exams] coming up.' (boy, 14, VI, late onset)

'When I first went there and they said that I've got an eye problem I thought 'Ob God what's going to happen to me? How bad is it?... I was just thinking, how I would cope in my normal life now because I had problems.' (boy, 12, VI, late onset)

Despite frequent worries and frustrations, many participants reported acceptance, psychological adjustment and a positive outlook on life, unrelated to age or nature of the visual impairment.

'Sometimes it's really annoying but I've got used to it. I have to get used to it because I can't change it.' (girl, 12, VT, early onset)

'Well I don't know what everyone else see like, so I think it's just normal.' (girl, 11, VI, early onset)

'I don't let things stand in my way.' (girl, 15, VI, early onset)

Resilience and adaptation were reported by most participants although some seemed to cope better than others.

'I have my good days and my bad days but it's just finding a way to get over it, you know, finding a way to deal with the good days and bad days.' (girl, 14, SVI, late onset)

'Because however I've been affected, it's not going to affect the future, because I've been coping with it so far, but I will, I should carry on coping with it' (boy, 13 years, blind, early onset)

\section{Future - Aspirations and fears}

Participants frequently spoke of their anxieties and hopes for their adult lives.

In schools there's things [adaptive technologies] to make things bigger ..., because of the boles in my vision. It's been sorted out, but in the future I need to make sure that I sort it out. Because there won't really be people to help... except mum, but she's not exactly going to come to work with me. So I have to kind of sort things out for myself'. (boy, 14, VI, late onset)

'But if people don't like things about my eyesight and stuff, they don't like the things that I do then they have to just learn and stuff. .....I'm not going to change how I live my lifestyle.' (boy, 13, blind, early onset) 
Whist they were generally well informed and aware of the challenges and potential restrictions for education and future careers, most had well considered ambitions and plans and talked positively about opportunities available to them.

'Another job that I might like to do is help other people that have bad eyesight. Because then I'd have some knowledge of people that can help you and different methods that you can use'. (boy, 14, VI, late onset)

I don't think [my eyesight] will get in the way. I will make sure that it doesn't mean that I don't get the job that I want. .' (boy, 10, SVI, early onset)

Importantly, their main concern was the potential occupational barriers imposed by others who might not trust their capabilities.

'If, say, there's a job going round and I've got an eyesight problem and someone else hasn't, then they'll probably pick the person who hasn't got the eyesight problem, because they will be easier to employ'. (boy, 15, VI, late onset)

If you get a job and the boss sees your eyes wobble they might think that you can't do something as well.' (girl, 12, VI, early onset)

The concerns about the challenges of independent living and mobility as adults included concerns relating to driving and using transport, even among younger participants. Being able to drive was more of a concern for boys.

I won't be allowed to drive so will have to either walk everywhere or catch the bus'. (girl, 11, VI, early onset)

People [other children at school] just keep on going on saying "I wonder what car I'm going to get when I'm older" and that, and then they ask me and that, and then I just say "I ain't going to be able to drive". I just get frustrated and annoyed.' (boy, 12, VI, late onset)

Regardless of age, many participants expressed concerns about establishing intimate relationships and many were conscious of the implications of hereditary eye condition for having children themselves. Nevertheless, many participants were positive about the future.

'If I did have a family and I had children, then I don't know if one of them would get it.' (boy, 14, VI, late onset) 
I'd quite like to have some kids, because I'm quite safe having because you have to have 2 people with the same gene to have this eyesight. [VI].' (girl, 15, VI, early onset)

\section{Functioning - school, home and leisure}

Participants reported functional restrictions and limitations on a daily basis, from every day leisure activities with friends and family to transport and school-based activities (e.g., reading restaurant menus, telling the difference between money when shopping, finding their seat in the cinema, getting the right bus, doing science experiments at school and reading signs, billboards and maps ).

'Instead of people reading it to you, I'd like to just be able to read it off the board but I can't'. It limits me, you know (boy, 14, VI, early onset)

T've always had more of a workload... have to remember more than anyone else. People say my memory is rubbish and it's true but they don't have to remember all the stuff I have to remember.' (girl, 13, VI, early onset)

They described the role of adaptive devices and accessible special technologies at school and home that enabled participation in activities with peers and families, as well as in self-guided leisure activities (e.g. listening to audio books, playing computer games, accessing social networking sites). Access to adaptive technologies and activity devices had a crucial role in enabling participation, but were not without disadvantages as reminders of the frustration and vulnerability associated with impaired functioning.

It's time consuming [text enlarging] to sort it all out and sometimes creates more problems than it solves. Moving a couple of centimetres more forward to read something is sometimes easier than having to go through all these long hours of photocopying everything.' (boy, 15, VI, late onset)

'When using special equipment] I feel like an idiot because I'm different to everybody else and I don't like it.' (boy, 11, blind, early onset)

Most interviewees actively participated in a variety of sports and leisure activities, both at school and home. In particular, some reported engaging, with their families, in accessible activity 
programmes run by various VI charities and organisations (e.g. skiing, climbing) that increased their opportunities for socialising.

I did make some friends through my eyesight so you can flip this on its head, because I went on one of those holiday things with [Royal National Institute for the Blind].' (girl, 15, VI, early onset)

\section{Treatment of eye condition}

Interviewees reported that visits to the ophthalmic team and treatment for the eye condition generated a sense of worry.

'They just say the same thing, we don't really know exactly what's wrong with you and there's nothing we can do'. (boy, 15, VI, late onset)

I had 2 operations.... I'm scared I'm going to wake up and them I'm still paralysed so I can't move'. (girl, 11, VI, early onset)

A consistent cause of frustration was the need to explain 'the story' repeatedly to different professionals within the team. Although some participants appreciated the complexity of their condition and the need for a large team of professionals to look after them, others viewed this experience as an indication that their voices were not being heard or that maybe professionals lacked the knowledge or training to deal with their condition.

I'd rather spend a little bit longer and have my eyes properly checked than someone who don't have a clue... I just don't think she [consultant] really knew what she was doing... I think they're not used to certain conditions of eyesight...give me like a decent doctor who know what they're doing cause that would give me more reason to go back there. I'd rather just see one and they've done it all. You see one wait another hour and see another one.' (boy, 14, VI, early onset)

By contrast, many participants were positive about eye-clinic appointments, tests and treatments, and saw their clinical team as a source of reassurance and information provision. They also expressed the importance of good communication with their doctor and appreciated having their say.

'I like to see if I've progressed.' (boy, 12, VI, early onset) 
'They're just really helpful because then they like talk to the school and then they said what I need, how I feel about my eyes and when I need rests and that'. (boy, 12, VI, late onset)

Only a small number of participants emphasised the drawbacks of missing school a for repeated eye-clinic visits. Most thought of it as a positive thing that allowed them to spend a day out with their family.

\section{DISCUSSION}

These interviews were undertaken for item generation for our VQoL questionnaire (Rahi et al., 2011), but provide insights into what it means to be a VI child. As reported here, the interviewees describe their own experiences of growing up with a visual disability and some of their current and future hopes and concerns, providing clinicians with knowledge to which they rarely have access.

The data show that, in addition to the many functional limitations, restrictions and lack of independence that these VI children experience, their visual disability contributes to social exclusion, stigma and isolation which sometimes results in feelings of frustration and vulnerability in terms of their privacy and self-esteem. They have significant worries and concerns for the future, from fears of being denied job opportunities to anxieties about establishing their own families.

The data also demonstrate how VI children are adaptable and able to find ways of enjoying opportunities available to them. Many talked about living with a visual impairment with acceptance, drawing strength from support from family and friends.

These findings resonate with previous research that has shown that VI children tend to have fewer friends than their sighted peers, more frequently report feelings of loneliness and low self-esteem and difficulties making friends, and tend to be more socially isolated and have smaller 
social networks that are limited to family members, relatives and other disabled peers(Jan et al., 1977; Van Hasselt, 1983; Huurre et al., 1999). Similarly, our findings suggest that establishing friendships can be difficult for VI children, particularly in mainstream schools where the feelings of isolation and exclusion seemed particularly prominent compared with those in specialist educational settings. Those children who mentioned having a good circle of friends had a tendency to talk positively about their QoL in keeping with research showing that well-being of adolescents with visual impairment is related to peer support (Kef, 1997; Kef \& Dekovic, 2004).

Our findings also revealed that routine eye clinic appointments can be stressful for children with visual impairment, especially for those with complex conditions that require longterm multidisciplinary care. It can be unclear to children why these appointments are necessary and why involvement of different specialists is required, particularly if there is no obvious change in their condition and thus, no obvious benefit to them. Better communication by clinicians could improve their patients' experience and reduce feelings of helplessness and frustration. This source of frustration might be addressed by demonstrating prior knowledge of patient history and avoiding repeated history taking where feasible.

The findings suggest that visual impairment does not launch a child or a young person onto a fixed trajectory of limited functional participation opportunities. Our participants described an impressive repertoire of activities at school, home and in their leisure time in which they engaged, from horse-riding and skiing, to climbing, kayaking and playing football. This reinforces the notion that appropriate adaptive technologies and sport and mobility devices (including specialist support like LSAs and TAs), combined with appropriate family and school support, are important in these children's lives and are a key to enabling their activity participation and successful functional outcomes. However, innovative and sensitive approaches may need to be further considered and developed, regarding how to implement these in the school settings. Clinical professionals might learn about their patients' lives by enquiring about these aspects rather than through more conventional questions e.g. about support at school. 
Equally, they may find it informative to know whether supportive approaches and adaptive technologies paradoxically lead to exclusion, setting the VI child apart.

The 'disability paradox' is a well-established notion whereby people with severe disabilities report high QoL and vice versa (Albrecht \& Devlieger, 1999; Kutner \& Nowels, 2003). This reaffirms the notion that functioning and/or health status are only some life facets that affect a person's perception of their QoL (Kuyken et al., 1995). Indeed, we found that many children with severe visual impairment show remarkable psychological adjustment and have ambitious plans and aspirations for the future. Positive emotional well-being and fulfilling social and emotional lives were reported by both those who have lived with visual disability from infancy/early childhood as well as those with later onset and/or progressive eye conditions. Our findings support the notion that hopes and expectations can be 're-adjusted' along the developmental pathway in the context of a health condition and disability (Sprangers \& Schwartz, 1999). Future research, with a view to developing appropriate psychosocial interventions for these children, should aim to address both the predisposing and protective factors that shape their QoL. A focus on identifying factors that contribute to positive adjustment in children with poor visual prognosis would be particularly informative. In the meantime, we hope that health professionals might find the narratives presented here interesting, enriching their understanding of the lives of their patients with visual disability, thus potentially enabling them better to support them.

\section{Key messages:}

- Children with visual disability emphasise the importance of family and peer support, balancing independence, support and safety, the emotional burden of and adjustment to living with a disability. 
- They live with concerns about their education and job prospects in the future and functional restrictions and limitations, and can find on-going management of their eye condition stressful.

- Despite a significant impact of visual disability on their daily lives, some children with visual impairment show resilience and are well adjusted. 


\section{References}

Albrecht, G. L., \& Devlieger, P. J. (1999). The disability paradox: high quality of life against all odds. Social Science \& Medicine, 48(8), 977-988.

Bullinger, M., \& Ravens-Sieberer, U. (1995). Health related quality of life assessment in children: A review of the literature. European review of applied psychology, 45(4), 245-256.

Curry, S. A., \& Hatlen, P. H. (1988). Meeting the unique educational needs of visually impaired pupils through appropriate placement. Journal of Visual Impairment \& Blindness, 82(10), $417-$ 424.

Davies, J., Wright, J., Drake, S., \& Bunting, J. (2009). 'By listening hard': Developing a serviceuser feedback system for adopted and fostered children in receipt of mental health services. Adoption \& Fostering, 33(4), 19-33.

Eiser, C., \& Morse, R. (2001). Quality-of-life measures in chronic diseases of childhood. Health Technol Assess, 5(4), 1-157.

Freeman, R. D., Goetz, E., Richards, D. P., \& Groenveld, M. (1991). Defiers of negative prediction: A 14-year follow-up study of legally blind children. Journal of Visual Impairment \& Blindness.

Garth, B., \& Aroni, R. (2003). 'I value what you have to say'. Seeking the perspective of children with a disability, not just their parents. Disability \& Society, 18(5), 561-576.

Gibson, F., Aldiss, S., Horstman, M., Kumpunen, S., \& Richardson, A. (2010). Children and young people's experiences of cancer care: A qualitative research study using participatory methods. International Journal of Nursing Studies, 47(11), 1397-1407.

Hatton, D. D., Bailey, D. B., Burchinaland, M. R., \& Ferrell, K. A. (1997). Developmental Growth Curves of Preschool Children with Vision Impairments. Child Development, 68(5), 788-806.

Horstman, M., \& Bradding, A. (2002). Helping children speak up in the health service. European Journal of Oncology Nursing, 6(2), 75-84.

Huurre, T. M., Komulainen, E. J., \& Aro, H. M. (1999). Social support and self-esteem among adolescents with visual impairments. Journal of $V$ isual Impairment \& Blindness, 93(1), 26-37.

Jan, J. E., Freeman, R. D., \& Scott, E. P. (1977). Visual impairment in children and adolescents: Grune \& Stratton.

Kef, S. (1997). The personal networks and social supports of blind and visually impaired adolescents. Journal of Visual Impairment and Blindness, 91(3), 236-244.

Kef, S. (2002). Psychosocial adjustment and the meaning of social support for visually impaired adolescents. Journal of Visual Impairment and Blindness, 96(1), 22-37.

Kef, S., \& Dekovic, M. (2004). The role of parental and peer support in adolescents well-being: A comparison of adolescents with and without a visual impairment. Journal of Adolescence, 27(4), 453-466.

Klostermann, B. K., Slap, G. B., Nebrig, D. M., Tivorsak, T. L., \& Britto, M. T. (2005). Earning trust and losing it: adolescents' views on trusting physicians. [Research Support, Non-U.S. Gov't]. Journal of Family Practice, 54(8), 679-687.

Kutner, J. S., \& Nowels, D. E. (2003). Confirmation of the "disability paradox" among hospice patients: Preservation of quality of life despite physical ailments and psychosocial concerns. Palliative \& supportive care, 1(3), 231-237.

Kuyken, W., Orley, J., Power, M., Herrman, H., Schofield, H., \& Murphy, B. (1995). The World Health Organization quality of life assessment (WHOQOL): position paper from the World Health Organization. Soc sci med, 41(10), 1403-1409.

McConachie, H. R., \& Moore, V. (1994). Early expressive language of severely visually impaired children. Developmental Medicine \& Child Neurology, 36(3), 230-240. 
Moules, T. (2009). 'They wouldn't know how it feels...': characteristics of quality care from young people's perspectives: a participatory research project. Journal of Child Health Care, 13(4), 322-332.

Nagle, K. M. (2001). Transition to Employment and Community Life for Youths with Visual Impairments: Current Status and Future Directions. Journal of Visual Impairment \& Blindness, 95(12), 725-738.

Ophir-Cohen, M., Ashkenazy, E., Cohen, A., \& Tirosh, E. (2005). Emotional status and development in children who are visually impaired. Journal of $V$ isual Impairment and Blindness, 99(8), 478.

World Health Organization (2003). International Statistical Classification of Diseases and Related Health Problems. 10th revision. Current version. Version for 2003. Chapter VII. H54. Blindness and low vision: World Health Organization.

Pelander, T., Lehtonen, K., \& Leino-Kilpi, H. (2007). International pediatric nursing. Children in the hospital: elements of quality in drawings. Journal of Pediatric Nursing, 22(4), 333-341.

Preisler, G. M. (1991). Early patterns of interaction between blind infants and their sighted mothers. Child: Care, Health and Development, 17(2), 65-90.

Rahi, J. S., \& Cable, N. (2003). Severe visual impairment and blindness in children in the UK. The Lancet, 362(9393), 1359-1365.

Rahi, J. S., Tadić, V., Keeley, S., Lewando-Hundt, G. (2011). Capturing children and young people's perspectives to identify the content for a novel vision-related quality of life instrument. Ophthalmology, 118(5), 819-824.

Shaw, A., Gold, D., \& Wolffe, K. (2007). Employment-Related Experiences of Youths Who Are Visually Impaired: How Are These Youths Faring? Journal of Visual Impairment \& Blindness, 101(1), 7-21.

Silver, C., \& Lewins, A. (2007). Using software in qualitative research: A step-by-step guide: Sage Publications Limited.

Sprangers, M. A. G., \& Schwartz, C. E. (1999). Integrating response shift into health-related quality of life research: a theoretical model. Social Science \& Medicine, 48(11), 1507-1515.

Tadić, V., Hamblion, E. L., Keeley, S., Cumberland, P., Hundt, G. L., \& Rahi, J. S. (2010). 'Silent Voices' in Health Services Research: Ethnicity and Socioeconomic Variation in Participation in Studies of Quality of Life in Childhood Visual Disability. Investigative Opthalmology \& Visual Science, 51(4), 1886-1890.

Taylor, D. (1997). The visually handicapped baby and the family. In D. K. Taylor (Ed.), Paediatric Ophthalmology (pp. 143-153). London: Blackwell Science Ltd.

Van Hasselt, V. B. (1983). Social adaptation in the blind. Clinical Psychology Review, 3(1), 87-102.

Warren, D. H. (1994). Blindness and children: An individual differences approach: Cambridge University Press. 